\title{
OPINION
}

\section{Coding the circumstances of injury: ICD-10 a step forward or backwards?}

\author{
John D Langley, David J Chalmers
}

\begin{abstract}
The International Classification of Diseases (ICD) $E$ codes are the most widely used coding frame for categorising the circumstances of injury and poisoning. In 1992 major revisions to the $\mathrm{E}$ codes were released. The aim of this paper was to consider whether the changes made are a step forward or backwards in terms of facilitating injury prevention.
\end{abstract}

The approach taken was to reflect on some former injury prevention research needs and the challenges they presented using data coded according to ICD-9, and then to consider how, if at all, ICD-10 has addressed these difficulties.

As with ICD-9, there are essentially two axes associated with each cause: intent and mechanism of injury, and these are captured by one code. This approach can have the unintended effect of hiding the significance of some mechanisms of injury. While there have been significant improvements in some areas, such as falls, in others, such as injuries due to firearms, ICD-10 has taken a step backward. In addition the failure to produce mutually exclusive codes presents problems for determining the incidence of downing events.

A welcome addition are "optional" activity codes which enable the identification of work related and sport related injury for the first time. Nevertheless, the limited range of codes and absence of coding guides limits their utility. The revised place of occurrence codes do not represent a significant improvement on ICD-9 in that they are limited to 10 , they are not mutually exclusive, and they do not adequately cover a range of specific places of occurrence.

In summary, relative to its predecessor, ICD-10 represents a significant improvement in many areas. Unfortunately, it still falls far short of the mark for many injury prevention needs.

(Injury Prevention 1999;5:247-253)

Keywords: methodology; surveillance

Internationally, the supplementary classification of external causes of injury and poisoning ( $\mathrm{E}$ codes) of the World Health
Organisation's (WHO) international statistical classification of diseases, injuries, and causes of death (International Classification of Diseases, ICD) is the most widely used coding frame for categorising the circumstances of injury and poisoning. ${ }^{1}$ The government agencies responsible for health statistics in most member countries of the WHO are currently using the ninth revision of ICD (commonly referred to as ICD-9) or a variation of it, such as the clinical modification (ICD-9-CM), ${ }^{2}$ to summarise their trauma deaths. In a limited number of countries, authorities are also using ICD-9 to code injuries resulting in hospital inpatient treatment. In addition, other agencies and individuals use $\mathrm{E}$ codes to summarise the circumstances of injury for injured persons presenting to other health service providers (for example general practitioners and emergency departments).

Despite their widespread use, these E codes have been criticised as being inadequate for

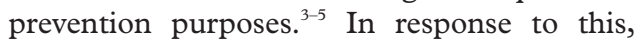
agencies both in New Zealand and in other countries have developed their own coding. ${ }^{6-8}$ In some instances these map to $\mathrm{ICD}^{7}$ but in others they do not. ${ }^{6}$

In 1992, the WHO released the 10th revision of ICD (ICD-10), ${ }^{9}$ which includes major revisions to the codes used to summarise injury and poisoning. Despite its release more than five years ago there has been no published review of its potential utility. New Zealand is a member of the WHO and proposes to introduce ICD-10 in 1999 to summarise its national statistics on fatalities and hospital discharges. In addition, at least one other major agency responsible for injury statistics in New Zealand is considering adopting ICD-10. It is thus timely to consider whether the changes made are a step forward or backwards in terms of facilitating injury prevention.

It is not practicable to critically examine all of the changes in detail. Rather, the approach taken here has been to reflect on some former injury prevention research needs in our country and the challenges they presented using data coded according to ICD-9, and then to consider how, if at all, ICD-10 has addressed these difficulties. 
Table 1 External causes of morbidity and mortality (V01-Y98)

\begin{tabular}{|c|c|}
\hline V01-X59 & Accidents \\
\hline V01-V99 & Transport accidents \\
\hline V01-V09 & Pedestrian injured in transport accident \\
\hline $\mathrm{V} 10-\mathrm{V} 19$ & Pedal cyclist injured in transport accident \\
\hline V20-V29 & Motorcycle rider injured in transport accident \\
\hline V30-V39 & Occupant of three wheeled motor vehicle injured in transport accident \\
\hline V40-V49 & Car occupant injured in transport accident \\
\hline V50-V59 & Occupant of pick-up truck or van injured in transport accident \\
\hline V60-V69 & Occupant of heavy transport vehicle injured in transport accident \\
\hline V70-V79 & Bus occupant injured in transport accident \\
\hline V80-V89 & Other land transport accidents \\
\hline V90-V94 & Water transport accidents \\
\hline V95-V97 & Air and space transport accidents \\
\hline V98-V99 & Other and unspecified transport accidents \\
\hline W00-X59 & Other external causes of accidental injury \\
\hline W00-W19 & Falls \\
\hline W20-W49 & Exposure to inanimate mechanical forces \\
\hline W50-W64 & Exposure to animate mechanical forces \\
\hline W65-W74 & Accidental drowning and submersion \\
\hline W75-W84 & Other accidental threats to breathing \\
\hline W85-W99 & $\begin{array}{l}\text { Exposure to electric current, radiation, and extreme ambient air temperature } \\
\text { and pressure }\end{array}$ \\
\hline X00-X09 & Exposure to smoke, fire, and flames \\
\hline $\mathrm{X} 10-\mathrm{X} 19$ & Contact with heat and hot substances \\
\hline $\mathrm{X} 20-\mathrm{X} 29$ & Contact with venomous animals and plants \\
\hline X30-X39 & Exposure to forces of nature \\
\hline $\mathrm{X} 40-\mathrm{X} 49$ & Accidental poisoning by and exposure to noxious substances \\
\hline $\mathrm{X} 50-\mathrm{X} 57$ & Overexertion, travel, and privation \\
\hline $\mathrm{X} 58-\mathrm{X} 59$ & Accidental exposure to other and unspecified factors \\
\hline $\mathrm{X} 60-\mathrm{X} 84$ & Intentional self harm \\
\hline X85-Y09 & Assault \\
\hline Y10-Y34 & Event of undetermined intent \\
\hline Y35-Y36 & Legal intervention and operations of war \\
\hline Y40-Y84 & Complications of medical and surgical care \\
\hline Y40-Y59 & $\begin{array}{l}\text { Drugs, medicaments, and biological substances causing adverse effects in } \\
\text { therapeutic use }\end{array}$ \\
\hline Y60-Y69 & Misadventures to patients during surgical and medical care \\
\hline Y70-Y82 & $\begin{array}{l}\text { Medical devices associated with adverse incidents in diagnostic and } \\
\text { therapeutic use }\end{array}$ \\
\hline Y83-Y84 & $\begin{array}{l}\text { Surgical and other medical procedures as the cause of abnormal reaction of } \\
\text { the patient, or of later complications, without mention of misadventure at } \\
\text { the time of the procedure }\end{array}$ \\
\hline Y85-Y89 & Sequelae of external causes of morbidity and mortality \\
\hline Y90-Y98 & $\begin{array}{l}\text { Supplementary factors related to causes of morbidity and mortality } \\
\text { classified elsewhere }\end{array}$ \\
\hline
\end{tabular}

Basic structure

In ICD-9 the external cause codes E codes constituted a supplementary classification. In ICD-10 they are now within the main body of the classification (chapter 20). The clear intent is that both the nature of injury and the external cause are to be coded. The basic structure is presented in table 1 . This is supplemented by a revised "place of occurrence code" and the introduction of an "activity code".

Those familiar with the ICD-9 E codes will notice the introduction of an alphanumeric coding system consisting of one letter followed by three numerals. This allows for a greater number of codes and provides room for expansion-two significant limitations of the $\mathrm{E}$ codes in ICD-9.

As with ICD-9, there are essentially two axes associated with each cause: intent and mechanism of injury, and these are captured by one code. Intent takes precedence in the classification, with mechanism being coded within each intent category. This approach can have the unintended effect of hiding the significance of some mechanisms of injury, an increasing primary focus of the injury control community. For example, those concerned to control mortality and morbidity due to firearms have sought to promote their concerns by illustrating the public health significance of firearm injury irrespective of intent. In response to this situation, external cause groupings that allow uniform aggregation of injury deaths by mech- anism and intent have been developed. ${ }^{10}$ However, as is illustrated below, the utility of these in terms of mechanism is limited by the variation in the degree of specificity of mechanism within the intent categories. Although this approach is useful, it is based on a fundamental structural weakness that can only be overcome by having separate codes for mechanism and intent.

Another disappointing aspect of the framework is the WHO's persistence of use of the term "accident" to refer to unintentional injury events. The scientific community has criticised the use of this term ${ }^{11-13}$ and, in response, public health agencies, both in New Zealand and overseas, have adopted alternative terms and have encouraged the media to do likewise.

\section{Transport accidents V01-V99}

There has been considerable interest world wide in promoting bicycle helmet wearing and, in particular, mandatory wearing, to reduce head injury. New Zealand has been part of this movement, introducing mandatory helmet wearing laws in 1994. One piece of information policymakers needed when considering the merits of mandatory helmet wearing was how many bicyclists sustained head injuries in traffic crashes each year. Such information is also important for monitoring the effect of any law, but it was not possible using ICD-9 codes to identify all bicycle crashes on public roads.

Bicyclists injured in motor vehicle traffic crashes were easily identified under E810E819: "motor vehicle traffic accidents" by reference to the fourth digit. This describes the type of road user. Bicyclists injured in nonmotor vehicle traffic crashes were classified under E826: "pedal cycle accidents". Because many of the latter would have been non-traffic crashes, it was not possible to accurately determine the total number of traffic only crashes, irrespective of motor vehicle involvement. Fortunately, the New Zealand Health Information Service identified this problem very early on, and, instead of using ICD-9's road user codes for the fourth digit level, instead used place of occurrence codes. Thus, a bicycle crash that only involved a bicycle and which occurred on a public road could be distinguished from the same type of crash that occurred on a farm because they had different place of occurrence codes (that is, .1 for farm, and .5 for street and highway).

This difficulty has disappeared with the introduction of ICD-10, since at the three character level the coding frame has been organised on the basis of road user and the fourth digit provides information on whether the victim was the cyclist or passenger and whether the incident was traffic or non-traffic. The relevant codes for pedal cyclists are shown in table 2. For other road users the same approach is used.

Unfortunately, this change is an inefficient way of coding transport crashes. A modular coding frame which had codes for the class of road user, whether the crash was traffic or nontraffic, and the type of crash, would involve far 
Table 2 Pedal cyclist injured in transport accident (V10-V19)

$\begin{array}{ll}\text { The following fourth character subdivisions are for use with categories V10-V18: } \\ .0 & \text { Driver injured in non-traffic accident } \\ .1 & \text { Passenger injured in non-traffic accident } \\ .2 & \text { Unspecified pedal cyclist injured in non-traffic accident } \\ .3 & \text { Person injured while boarding or alighting } \\ .4 & \text { Driver injured in traffic accident } \\ .5 & \text { Passenger injured in traffic accident } \\ .9 & \text { Unspecified pedal cyclist injured in traffic accident } \\ \text { V10 } & \text { Pedal cyclist injured in collision with pedestrian or animal } \\ \text { V11 } & \text { Pedal cyclist injured in collision with other pedal cycle } \\ \text { V12 } & \text { Pedal cyclist injured in collision with two or three wheeled motor vehicle } \\ \text { V13 } & \text { Pedal cyclist injured in collision with car, pick-up truck, or van } \\ \text { V14 } & \text { Pedal cyclist injured in collision with heavy transport vehicle or bus } \\ \text { V15 } & \text { Pedal cyclist injured in collision with railway train or railway vehicle } \\ \text { V16 } & \text { Pedal cyclist injured in collision with other non-motor vehicle } \\ \text { V17 } & \text { Pedal cyclist injured in collision with fixed or stationary object } \\ \text { V18 } & \text { Pedal cyclist injured in non-collision transport accident } \\ \text { V19 } & \text { Pedal cyclist injured in other and unspecified transport accidents }\end{array}$

V19

fewer codes and thus be less prone to error due to ambiguity. In addition it would allow users the opportunity to add one new code for any of the three dimensions without having to replicate all the codes in table 2 .

For example, ICD-10 has a group of 10 codes for "occupant of pick-up truck or van injured in transport accident" (V50-V59). From a prevention perspective it may be important to determine whether the vehicle was a van as opposed to a pick-up truck. Using the present ICD-10 model, one would presumably allocate V50-V59 to, say, pick-up truck and then create another group of 10 codes for vans. Using a modular coding frame would simply require the addition of one code to, say, a vehicle type coding frame. If this was two characters in length it would accommodate 100 different vehicles.

There has been considerable concern in recent times about the rising number of all terrain vehicle (ATV) crashes. ${ }^{14}$ The term ATV is used in New Zealand to refer exclusively to three or four wheel vehicles specifically designed for off-road use. It should be noted also that, in contrast to some other countries, ATVs

Table 3 Accidental falls codes

\begin{tabular}{|c|c|c|c|}
\hline \multicolumn{2}{|l|}{$I C D-9$} & \multicolumn{2}{|c|}{$I C D-10$} \\
\hline E880 & Fall on or from stairs or steps & W00 & Fall on same level involving ice and snow \\
\hline E880.0 & Escalator & W01 & $\begin{array}{l}\text { Fall on same level from slipping or tripping and } \\
\text { stumbling }\end{array}$ \\
\hline E880.9 & Other stairs or steps & W02 & $\begin{array}{l}\text { Fall involving ice skates, skis, rollerskates, or } \\
\text { skateboards }\end{array}$ \\
\hline E881 & Fall on or from ladders or scaffolding & W03 & $\begin{array}{l}\text { Other fall on same level due to collision with, } \\
\text { or pushing by, another person }\end{array}$ \\
\hline E881.0 & Fall from ladder & W04 & $\begin{array}{l}\text { Fall while being carried or supported by other } \\
\text { persons }\end{array}$ \\
\hline E881.1 & Fall from scaffolding & W05 & Fall involving wheelchair \\
\hline E882 & Fall from or out of building or other structure & W06 & Fall involving bed \\
\hline E883 & Fall into hole or other opening in surface & W07 & Fall involving chair \\
\hline E883.0 & $\begin{array}{l}\text { Accident from diving or jumping into water } \\
\text { (swimming pool) }\end{array}$ & $\begin{array}{l}\text { W08 } \\
\text { W09 }\end{array}$ & $\begin{array}{l}\text { Fall involving other furniture } \\
\text { Fall involving playground equipment }\end{array}$ \\
\hline E883.1 & Accidental fall into well & W10 & Fall on and from stairs and steps \\
\hline E883.2 & Accidental fall into storm drain or manhole & W11 & Fall on and from ladder \\
\hline E883.9 & Fall into other hole or other opening in surface & W12 & Fall on and from scaffolding \\
\hline $\mathrm{E} 884$ & Other fall from one level to another & W13 & $\begin{array}{l}\text { Fall from, out of or through building or } \\
\text { structure }\end{array}$ \\
\hline E884.0 & Fall from playground equipment & W14 & Fall from tree \\
\hline E884.1 & Fall from cliff & W15 & Fall from cliff \\
\hline $\mathrm{E} 884.2$ & Fall from chair or bed & W16 & $\begin{array}{l}\text { Diving or jumping into water causing injury } \\
\text { other than drowning or submersion }\end{array}$ \\
\hline E884.9 & Other fall from one level to another & W17 & Other fall from one level to another \\
\hline E885 & Fall on same level from slipping, tripping, or stumbling & W18 & Other fall on same level \\
\hline E886 & $\begin{array}{l}\text { Fall on same level from collision, pushing or shoving, } \\
\text { by or with other person }\end{array}$ & W19 & Unspecified fall \\
\hline E886.0 & In sports & & \\
\hline E886.9 & Other and unspecified & & \\
\hline E887 & Fracture, cause unspecified & & \\
\hline E888 & Other and unspecified fall & & \\
\hline
\end{tabular}

are used almost exclusively for work related activity, mainly on farms. Unfortunately, it has not been possible to identify these incidents using ICD-9. Although provision is made in ICD-10 for coding crashes that involve three wheeled motor vehicles, it is intended that these apply only to vehicles "...designed primarily for on-road use" (p1020). The three and four wheeled vehicles of concern in New Zealand and would be more appropriately designated as "special ATVs". Specific provision has been made in ICD-10 to code crashes involving these vehicles (that is, V86: occupant of special all-terrain or other motor vehicle designed primarily for off-road use, injured in transport accident). This classification, however, would also include two wheeled motorcycles specifically designed for off road use. Further codes are thus needed to distinguish between two, three, and four wheeled special ATVs or other motor vehicles designed primarily for off-road use.

\section{Falls W00-W19}

As in many other western countries, falls are the leading cause of injury morbidity in New Zealand. Table 3 compares ICD-9 codes with ICD-10 codes.

Langley and Chalmers, in a review of falls data, recommended that on the basis of incidence, consideration be given to having unique codes for falls from: ladders (separated from scaffolds), beds, chairs, other furniture, jungle gyms, trampolines, other playground and sports equipment, mountains, banks, trees, and other natural features. ${ }^{15}$ Five of these categories have unique codes in ICD-10. The removal of "E887: fracture unspecified" from the falls codes in ICD-10 is appropriate given that its inclusion was based purely on an assumption that in the absence of information 
Table 4 ICD falls exclusions

\begin{tabular}{|c|c|}
\hline$I C D-9$ & $I C D-10$ \\
\hline $\begin{array}{l}\text { Burning building (E890.8, E891.8) } \\
\text { Into fire (E890-E899) } \\
\text { Into water (with submersion or drowning) } \\
\quad \text { (E910.-) } \\
\text { Machinery (in operation) (E919.-) } \\
\text { On edged, pointed, sharp object (E920.-) } \\
\text { Transport vehicle (E800-E845) } \\
\text { Vehicle not elsewhere classifiable (E846-E848) }\end{array}$ & $\begin{array}{l}\text { Assault (Y01-Y02) } \\
\text { Fall (in) (from) } \\
\text { - Animal (V80.-) } \\
\text { - Burning building (X00.-) } \\
\text { - Into fire (X00-X04, X08-X09) } \\
\text { - Into water (with drowning or } \\
\text { submersion) (W65-W74) } \\
\text { - Machinery (in operation) (W28-W31) } \\
\text { - Transport vehicle (V01-V99) } \\
\text { Intentional self harm (X80-X81) }\end{array}$ \\
\hline
\end{tabular}

to the contrary, a fracture most probably resulted from a fall-hence the inclusion of this category among the fall codes in ICD-9.

One characteristic of ICD-9 is that the external cause codes are often not mutually exclusive. The codes for falls illustrate this. Table 4 lists the types of falls that ICD-9 and ICD-10 direct be classified elsewhere.

Exclusions such as these make it difficult to obtain accurate estimates of the incidence of specific classes of events or the relative significance of categories within them. In 1987 in New Zealand there were an estimated 773 falls from horses resulting in inpatient treatment. These were coded under E828: accident involving an animal being ridden. ${ }^{16}$ This number substantially exceeded that due to falls from: ladders and scaffolds E881 $(n=503)$, out of building or other structures E882 ( $\mathrm{n}=661)$, and fall into hole or opening in surface E883 $(n=162)$. Given the generic nature of some of the falls codes, and the large number of events coded to them, ${ }^{17}$ it is unfortunate that an opportunity to identify a significant class of event, for which there are injury control options (for example helmets for riders), was lost using ICD-9. The situation is no better in ICD-10, as persons injured as a result of a fall from a horse would be coded V80: animal-rider or occupant of animal-drawn vehicle injured in transport accident.

\section{Exposure to inanimate mechanical forces W20-W49: firearms}

From a public policy perspective it is important to be able to differentiate between handguns, long guns, military style semiautomatic firearms, and air guns/rifles. ${ }^{18}$ Although firearm types have been elevated in status from the fourth digit level in ICD-9 to the three character level in ICD-10, there is a substantial loss of information on firearm type for countries that currently code at the four digit level using

Table 5 Codes for unintentional firearm injuries

\begin{tabular}{llll}
\hline ICD-9 & & ICD-10 \\
\hline E922 & $\begin{array}{c}\text { Accident caused by firearm } \\
\text { missle }\end{array}$ & $\begin{array}{l}\text { W32 } \\
\text { W33 }\end{array}$ & $\begin{array}{c}\text { Handgun discharge } \\
\text { Rifle, shotgun, and larger firearm } \\
\text { discharge } \\
\text { Discharge from other and unspecified } \\
\text { firearm }\end{array}$ \\
E922.1 & Handgun & W34 & \\
E922.2 & Shotgun (automatic) & & \\
E922.3 & Military firearms & & \\
E922.8 & Other & & \\
E922.9 & Unspecified & & \\
\hline
\end{tabular}

ICD-9 (table 5). Whereas shotguns and military firearms were separate codes in ICD-9 they have now been lumped together (W33). Given the growing concern of many countries to control firearm injuries, this loss of specificity is inappropriate.

In ICD-9, unintentional airgun injuries are coded E917: striking against or struck accidentally by objects. In ICD-10 they are coded under W34: discharge from other and unspecified firearms. This is an appropriate change, but one is still unable to distinguish between airguns and other firearms. Although airgun injuries are not as serious as powder firearm injuries, they account for a significant personal and social burden, and as such, warrant a specific code. ${ }^{1920}$

\section{Accidental drowning and submersion W65-W74}

Those new to ICD external cause of injury codes could be forgiven for assuming that this group of codes deals with all unintentional drowning and submersion incidents. It does not. For example, in ICD-9, drownings in water transport incidents are coded under transport codes (E830: accident to watercraft causing submersion). Regrettably, this approach has been continued in ICD-10. Admittedly, those familiar with such nuances are able to arrive at a more accurate estimate of unintentional drowning, but the coding still results in underestimates.

For example, drownings due to motor vehicle crashes, like those due to road traffic crashes, are coded elsewhere. In this case, however, the fact that a drowning was involved is not apparent by reference to the $\mathrm{E}$ code (for example, E816: motor vehicle traffic accident due to loss of control, without collision on the highway). This problem can be overcome by reference to injury diagnoses, but unfortunately some countries still do not code the diagnoses of injuries causing deaths. Drownings due to motor vehicle crashes account for a significant proportion of all drowning deaths and opportunities for prevention may be overlooked. $^{21}$

Table 6 compares ICD-9 codes with those in ICD-10. In ICD-9 the emphasis was on obtaining detail of the nature of any recreational activity at the time of the event. In contrast, ICD-10 has opted for detail on the nature of the body of water, and, in the case of bathtub and swimming pool incidents, distinguishes normal activity (bathing, swimming) from unintended activity (falls). Given that some countries have laws for the fencing of swimming pools, these changes are welcome. However, the changes have been at the cost of losing information on the activity at the time of the incident. It should be noted in this context that water skiing, diving, swimming - all activities that were previously identified in ICD9 - cannot be identified using the activity codes introduced in ICD-10. 
Table 6 Accidental drowning and submersion codes

\begin{tabular}{|c|c|c|c|}
\hline \multicolumn{2}{|l|}{$I C D-9$} & \multicolumn{2}{|c|}{$I C D-10$} \\
\hline E910 & Accidental drowning and submersion & W65 & Drowning and submersion while in bathtub \\
\hline E910.0 & While water skiing & W66 & Drowning and submersion following fall into bathtub \\
\hline E910.1 & $\begin{array}{l}\text { While engaged in other sport or recreational activity } \\
\text { with diving equipment }\end{array}$ & $\begin{array}{l}\text { W67 } \\
\text { W68 }\end{array}$ & $\begin{array}{l}\text { Drowning and submersion while in swimming pool } \\
\text { Drowning and submersion following fall into }\end{array}$ \\
\hline E910.2 & $\begin{array}{l}\text { While engaged in other sport or recreational activity } \\
\text { without diving equipment }\end{array}$ & W69 & $\begin{array}{l}\text { swimming pool } \\
\text { Drowning and submersion while in natural water }\end{array}$ \\
\hline E910.4 & $\begin{array}{l}\text { While swimming or diving for purposes other than } \\
\text { recreation or sport } \\
\text { In bathtub }\end{array}$ & W70 & $\begin{array}{l}\text { includes: lake, open sea, river, stream } \\
\text { Drowning and submersion following fall into natural } \\
\text { water }\end{array}$ \\
\hline E910.8 & Other & W73 & $\begin{array}{l}\text { Other specified drowning and submersion includes: } \\
\text { quenching tank, reservoir }\end{array}$ \\
\hline E910.9 & Unspecified & W74 & $\begin{array}{l}\text { Unspecified drowning and submersion includes: } \\
\text { drowning NOS, fall into water NOS }\end{array}$ \\
\hline
\end{tabular}

NOS $=$ not otherwise specified.

\section{Contact with heat and hot substances X10-X19}

The codes for this group of events are a marked improvement on ICD-9 (table 7), which was of little value from a prevention perspective. ${ }^{5}$ Particularly welcome is a unique code for tap water. There has been concern for some time about the high temperatures of domestic hot tap water and the resulting burns. ${ }^{22}{ }^{23}$ Unfortunately, it is rarely possible to obtain an accurate estimate of the incidence of such burns because ICD-9 does not specifically identify them. Furthermore, the narrative that accompanied the codes on New Zealand's national mortality and morbidity (inpatient) files frequently described the event as being due to "hot water". ${ }^{24}$

Burns due to "caustic and corrosive material" are covered by the new category. Reference to the ICD-10 index indicates that these should be coded to X49: "accidental poisoning exposure to other and unspecified chemicals and noxious substances". The rationale for this change is not apparent.

\section{Intentional self harm X60-X84 and assault X85-Y09}

For no apparent reason the range of codes available in ICD-9 for some categories of unintentional injury is different to that for intentional injury. For example, there were only 10 three digit codes for suicide and self inflicted injury, and 10 for homicide and injury purposefully inflicted by other persons. Thus, while it was possible, at the three digit level, to determine the incidence of those who had been unintentionally injured by use of a firearm (E922: accident caused by firearm missile), it was not possible to do this for homicide and

Table 7 Hot substance codes

\begin{tabular}{|c|c|c|c|}
\hline \multicolumn{2}{|l|}{$I C D-9$} & \multicolumn{2}{|c|}{$I C D-10$} \\
\hline E924 & $\begin{array}{l}\text { Accident caused by hot substance } \\
\text { or object, caustic or corrosive } \\
\text { material, and steam }\end{array}$ & $\begin{array}{l}\mathrm{X} 10 \\
\mathrm{X} 11\end{array}$ & $\begin{array}{l}\text { Contact with hot drinks, foods, fats, and } \\
\text { cooking oils } \\
\text { Contact with hot tap water }\end{array}$ \\
\hline E924.1 & Caustic and corrosive substances & $\mathrm{X} 12$ & Contact with other hot fluids \\
\hline E924.0 & $\begin{array}{l}\text { Hot liquids and vapours including } \\
\text { steam }\end{array}$ & $\begin{array}{l}\text { X13 } \\
\text { X14 }\end{array}$ & $\begin{array}{l}\text { Contact with steam and hot vapours } \\
\text { Contact with hot air and gases }\end{array}$ \\
\hline E924.8 & Other & $\mathrm{X} 15$ & Contact with hot household appliances \\
\hline E924.9 & Unspecified & $\mathrm{X} 16$ & $\begin{array}{l}\text { Contact with hot heating appliances, } \\
\text { radiators, and pipes }\end{array}$ \\
\hline & & $\mathrm{X} 17$ & $\begin{array}{l}\text { Contact with hot engines, machinery, } \\
\text { and tools }\end{array}$ \\
\hline & & $\mathrm{X} 18$ & Contact with other hot metals \\
\hline & & X19 & $\begin{array}{l}\text { Contact with other and unspecified heat } \\
\text { and hot substances }\end{array}$ \\
\hline
\end{tabular}

assault, or suicide and self inflicted injury, as the two codes included other explosive devices (for example, E955: suicide and self inflicted injury by firearms and explosives). This problem, however, was addressed by reference to fourth digit codes that provided greater specificity on the agent of injury (for example, E965.0: handgun).

Given the prominence in many countries of self inflicted injury and injury purposely inflicted by others, there was a need to address the restrictive range of codes. This has occurred to some degree in ICD-10. In the example referred to above, there are new three character level codes for unintentional, self inflicted, assaultive, and handgun injuries. Nevertheless, there are still too few categories. For example, as has been demonstrated above, there is a substantial range of codes for motor vehicle traffic crashes. This contrasts with self harm and assault where there is one code each, X82 and Y03 respectively. This example serves to highlight further the problems inherent in incorporating two dimensions, intent and mechanism, in one code. The obvious solution is to have a separate code for intent and another for mechanism.

\section{Activity codes}

New to the 10th revision are some "optional" activity codes. They are listed in table 8 . These are a welcome addition because their use enables the identification of work related and sport related injury for the first time. Non-ICD coded injury statistics demonstrate these are priority areas for injury prevention. For example, in New Zealand in 1997, new "entitlement" claims for compensation due to injury cost $\$ 193$ million, with $37 \%$ of this cost being for work related injury and $13 \%$ for sport. ${ }^{25}$ Unfortunately, the new ICD-10 codes are not mutually exclusive and there is no guidance on how to code a professional sports person injured in their occupation. Similarly, it is not clear from the new activity codes how bystanders in places of work or sport who get injured due to these activities should be classified.

Work related injury mortality and morbidity make a substantial contribution to the "all cause" injury mortality and morbidity burden. ${ }^{25}{ }^{26}$ This, coupled with the fact that in New Zealand, as in most other developed countries, there is a government agency whose 
Table 8 ICD-10 activity codes

While engaged in sport

While engaged in leisure activity

While working for income

While engaged in other types of work

While resting, sleeping, eating, or engaged in other

vital activities

While engaged in other specified activities

During unspecified activities

mandate it is to manage this problem, is sufficient reason for having a separate field for identifying whether an injury was work related or not.

While it is useful to be able to determine the incidence of sports injuries, those involved in prevention need to know, as a minimum, the type of sport involved. Given the diversity of sports internationally, arriving at an international coding frame presents a challenge. That there is a need is well illustrated by the introduction of sports codes in ICD-9-AM.

\section{Place of occurrence codes}

The ICD-10 codes for place of occurrence are listed in table 9 . The instructions state that they are to be used with W00-Y34 except Y06.and Y07.- (see table 1).

Several shortcomings in the ICD-9 place of occurrence codes have been identified previously. ${ }^{27}$ The revised codes do not represent a significant improvement in that they are limited to 10 , are not mutually exclusive, and do not adequately cover the range of specific places of occurrence. On a positive note, in contrast to ICD-9, the instructions recommend that the codes be applied to a wider range of events. For example, under ICD-9, place of occurrence was not recorded for intentional injuries. Nevertheless, it is unclear why the instructions are still restrictive. For example, there was a recent need in New Zealand to determine whether "motorcycle riders injured in transport non-traffic accidents" were being injured on farms. ${ }^{14}$ The use of place of occurrence codes would have provided this information.

\section{Implications for prevention}

Relative to its predecessor, ICD-10 represents a significant improvement in many areas. Unfortunately, it still falls far short of the mark for many injury prevention needs. Some would argue that ICD was not designed to meet many of the expectations implicit in the above discussion. This may be true, but it is also the case that many agencies and individuals seek a more useful coding frame than ICD. One need look no further than the development of alter-

Table 9 ICD-10 place of occurrence codes

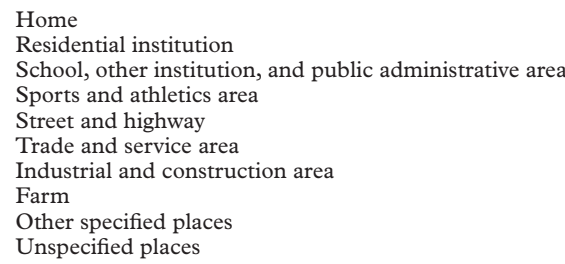

native coding frames in New Zealand, Australia, and Scandinavia. It is undoubtedly the case that this need will persist and grow as injury receives increasing recognition, proportionate to its impact on health status. In the absence of some internationally agreed classifications for meeting these needs there is bound to be an increasing proliferation of such frames. These are likely to be poorly thought out, incompatible with one another, and unable to be mapped to ICD.

While this critique has largely been made from a New Zealand perspective, most of the shortcomings identified have implications for other countries. Given the central place the ICD has in coding the circumstances of injury it is surprising that it took five years from first publication before a critique of it was published. That delay, coupled with the relative dearth of subsequent critiques, may account for the shortcomings in ICD-10. The latter was published in 1992. Are we about to repeat history for revisions to ICD-10 or the development of ICD-11? The task of developing coding frames to meet the needs of injury practitioners has been taken up by the WHO Working Group on Injury Surveillance Methodology Development. That group released its draft proposal of the International Classification for External Causes of Injury (ICECI) at the 4th World Conference on Injury Prevention and Control in Amsterdam. ${ }^{28}$

In developing ICECI three steps have been taken. First, unravelling the one dimensional structure of ICD external cause into three essential dimensions that the ICD designers collapsed into one: "intent", "mechanism", and "object involved in the injury event". Second, adding additional codes to these three data items as well as to the activity and place items. Third, development of additional sets of items that are specifically relevant for one or two subsets of cases such as traffic related injuries or injuries due to violence.

This research was undertaken under the core funding of the Injury Prevention Research Unit. Core funding is provided by the Health Research Council of New Zealand and the Accident Rehabilitation and Compensation Insurance Corporation. This paper is based on a presentation made at a meeting in Amsterdam, on 16 and 17 May 1998, of the International Collaborative Effort on Injury Statistics sponsored by the US National Center for Health Statistics (CDC) and co-funded by the US National Institute of Child Health and Human Development (NIH). The Institute of Child Health and Human Development (NIH). The comments of attenders at that meeting are appreciated. The comments of Jonathan Alsop, New Zealand Health Information Service, Donna Pickett, Elizabeth McLoughlin, Johan Lund, James Harrison, and Gordon Smith on earlier versions of this
paper are also appreciated.

1 World Health Organisation. International classification of diseases -9th revision. Geneva: WHO, 1977.

2 National Centre for Health Statistics. International classification of diseases, 9th revision, clinical modification. Ann Arbor: Commission on Professional and Hospital Activities, 1979

3 Baker SP. Injury classification and the international classification of diseases codes. Accid Anal Prev 1982;14:199-201.

4 Langley J. The international classification of diseases codes for describing injuries and the circumstances surrounding injuries: a critical comment and suggestions for improvement. Accid Anal Prev 1982;14:195-7.

5 Langley J. Description and classification of childhood burns. Burns 1984;10:231-5.

6 Heidenstrom PN. Accident recording: the need for a new approach. Accident Rehabilitation and Compensation Insurance Corporation Statistics 1982;1:4

7 National Injury Surveillance Unit. National data standards for injury surveillance. Adelaide, Australia: National Injury Surveillance Unit, Australian Institute of Health and Welfare, 1995. 
8 Nordic Medico-Statistical Committee. NOMESCO classification of external causes of injuries. Copenhagen: NOcation of extern

9 World Health Organisation. International statistical classification of diseases and related health problems -10 th revision. Geneva: WHO, 1992

10 US Department of Health and Human Services. Recommended framework for presenting injury mortality data Morb Mortal Wkly Rep 1997;46(RR-14):1-30.

11 Langley JD. The need to discontinue the use of the term "accident" when referring to unintentional injury events. Accid Anal Prev 1988;20:1-8.

12 Bijur PE. What's in a name? Comments on the use of the terms "accident" and "injury". Inj Prev 1995;1:9.

13 Loimer H, Driur M, Guarnieri M. Accidents and acts of God: a history of the terms. Am f Public Health 1996;86:101-7.

14 Langley J, Marshall S, Clarke J, et al. Motorcycle/ATV crashes on farms. Fournal of Occupational Health Safety 1995; 11:387-94.

15 Langley JD, Chalmers DJ. Unintentional falls resulting in death or hospitalisation. Contemporary Health Issues 1989;

16 Buckley SM, Chalmers DJ, Langley JD. Injuries due to falls from horses. Aust $\mathcal{F}$ Public Health 1993;17:269-71.

17 Langley JD. Frequency of injury events in New Zealand compared with the available E-codes. Methods Inf Med 1987;26:89-92

18 Minister of Police. Review of firearms control in New Zealand: summary and conclusions. Auckland: Government Print, 1997.
19 Langley JD, Alsop JC, Norton RN, et al. Airguns injuries in New Zealand, 1979-92. Inj Prev 1996;2:114-17.

20 Harrison J. ICD - coding of firearm injuries. http:// www.cdc.gov/nchswww/about/otheract/ice/guncodes.htm

21 Smith GS, Langley JD. Drowning surveillance: how well do E codes identify submersion fatalities. Inj Prev 1998;4:1359 .

22 Dickson N, Martin M, Waller AE. Hot water temperature in Dunedin homes with preschool children. N Z Med f 1990; 103:452-454.

23 Waller AE, Clarke JA, Langley JD. An evaluation of a program to reduce home hot tap water temperatures. Aust f Public Health 1993;17:116-23.

24 Waller AE, Marshall SW. Childhood thermal injuries in New Zealand resulting in death and hospitalization. Burns 1993;19:371-6.

25 Accident Rehabilitation and Compensation Insurance Corporation. Injury Statistics 1 fuly 1996 to 30 fune 1997. Wellington: Accident Rehabilitation and Compensation Insurance Corporation, 1998.

26 Cryer PC, Fleming C. A review of work-related fatal injuries in New Zealand 1975-84-numbers, rates and trends. NZ Med 7 1987;100:1-6.

27 Langley JD, Chalmers DJ. Place of occurrence of injury events in New Zealand compared with the available ICD codes. Methods Inf Med 1989;28:109-13.

28 World Health Organisation. International classification for external causes of injuries (ICECI) guidelines for counting and classifying external causes of injuries for prevention and control. Amsterdam: Consumer Safety Institute, WHO Collaboratng Center on Injury Surveillance, 1998.

\section{Culture makes continental roads four times as perilous}

Figures from Direct Line insurance show that British drivers have a one in three chance of making a claim from driving abroad, compared with only one in five at home. Government research figures place Great Britain near the top of the European driving safety table with 6.3 road deaths per 100000 population. Spain scores 14 deaths per 100 000, Greece 22.5, and Portugal 28.9 (OECD International Road Traffic and Accident Database). A traffic psychologist, who worked on the Social Attitudes to Road Traffic Risk in Europe Survey, has stated that national characteristics come out in driving. Thus the Dutch are safety conscious because they see it as a social issue, while the British are a tweedy bunch who tut-tut at other drivers' speeding (The Times (London), 22 May 1999).

Editor's note: This was spotted by regional correspondent, Rosie Mercer, who is from Northern Ireland. She asks what would the psychologist make of the Irish? Read on ...

"Car hire firm is sued for leasing to an Irishman"

The family of a young woman from Kilsheelan in County Tipperary, who was killed in a drink-driving crash, is suing one of America's largest car rental companies claiming that they should never have let the driver have a vehicle because he was Irish and therefore, bound to get drunk. The lawsuit was filed in Orange County saying the Dollar Rent-a-Car "either knew or should have known about the unique cultural and ethnic customs existing in Ireland which involve the regular consumption of alcohol at pubs as a major component of Irish social life". It went on to state that the defendant "would have a high propensity to drink alcohol while in the United States and operate the vehicle in a grossly negligent manner including, but not limited to, drinking and driving". A spokesman from Dollar described the lawsuit as absurd. "The plaintiff's attorney is saying we have a duty to violate the Constitution of the United States, to discriminate against people based on their national origin". The case drew so many protests from Irish-Americans that the family's lawyer had to apologise and amend the lawsuit (Daily Telegraph (London), 20 May 1999).

Editor's note: Our regional correspondent from the Emerald Isle would no doubt have more to say than this! 